\title{
AC 2007-1103: ENHANCING MINORITY ENGINEERING EDUCATION AT AAMU THROUGH DOE SPONSORED PROJECT
}

\section{Cathy Qian, Alabama A\&M University}

Dr. Cathy Qian is an Associate Professor of the Department of Mechanical Engineering at Alabama A\&M University in Huntsville, AL. Dr. Qian earned her Ph.D. and M.S. in Mechanical Engineering from the University of Tennessee. Dr. Qian is the principal investigator of the high performance computing research and education project at AAMU.

\section{Zhengtao Deng, Alabama A\&M University}

Dr. Z.T. Deng is an Associate Professor of the Department of Mechanical Engineering at Alabama A\&M University in Huntsville, AL. Dr. Deng has an extensive background and research experience in Computational Fluid Dynamics numerical simulation in particular high-speed aerodynamics/flows with heat transfer phenomena. He earned his Ph.D., Aerospace Engineering, University of Tennessee, 1991.

\section{George Seweryniak, DoE}

U.S. Department of Energy MICS Program Manager. 


\title{
Enhancing Minority Engineering Education at AAMU through DoE Sponsored Project
}

\begin{abstract}
This paper describes our experience in enhancing minority engineering education at Alabama A\&M University through a DOE Sponsored project. Strategies, activities and outcome were discussed in the following area: (1) Establishment and enhancement of high performance computing laboratory at AAMU; (2) Training of minority graduate and undergraduate students in computational science and engineering; (3) DOE Computational Science scholarship program at AAMU; and (4) Minority undergraduate summer research interns at the computational science division of Oak Ridge National Lab (ORNL). Outcome assessment was discussed.
\end{abstract}

\section{Introduction}

According to the US 1990 census, the total US population was $248,709,873$ in 1990 . Of these, approximately 51\% were women, 29,986,060 (or 12\%) were African American, 22,354,059 (or 9\%) Hispanic, and 1,878,285 (or 1\%) Native American. In 1995, of the total 132 million U.S. civilian labor forces, only 5500 African American who had Ph.D. degree in Science, Mathematics, Engineering and Technology (SMET) were employed in the SMET field. Only 5.6\% of the enrollment in SMET of graduate schools were African American, Hispanic American and Native American (AAHANA) students. There is an urgent need to train minority students in SMET field [1]. Historically Black Colleges and Universities (HBCUs) are the primary source of African-American scientists in the US, and HBCU participation in training of students in SMET field is critical.

To respond to these critical needs, the U.S. Department of Energy (DOE) Mathematics, Information and Computational Sciences (MICS) division created an Alliance for Computational Science Collaboration in 1997. Strategies designed to help produce future DOE minority scientists and engineers are: (1). To involve HBCU students and faculty members in computational science projects at national laboratories and research institutions; (2). To assist HBCU faculty members in integrating interdisciplinary computational science courses into their undergraduate curricula, involving freshmen to senior students; and (3). To provide support and expertise to HBCU researchers using state-of-the-art computational science technologies and methodologies.

Alabama A\&M University (AAMU) is one of the HBCU members. In 1999, DOE-MICS awarded AAMU a Grant to conduct High performance computational (HPC) science research and education [2]. In 2003, a new DOE grant was awarded to AAMU to continue this effort [3]. The goal was to encourage faculty and students to become more involved in computational science activities through establishment of high performance computing laboratory, computational science research, student scholarship, student internship, student research, and collaborative research involving ORNL scientists. In the past six years, 
significant impacts have been made to AAMU minority engineering education. The DOE project broadens the research and educational capability at AAMU. It was proved that this project not only created huge attraction to top minority science and engineering students but also enhanced the retention of minority engineering students. More important, it provided a pipeline for minority students in graduate studies. This paper describes the four elements of the project to enhance minority engineering education at AAMU.

\section{Establishment and Enhancement of High Performance Parallel Computing Laboratory}

Under the support of DOE in 2003, AAMU was able to establish a high performance computing (HPC) laboratory using a cluster of Linux workstations. The HPC lab was enhanced through continuous support of DOE. Currently, the HPC lab has 8 high performance LINUX workstations, two Sun Ultra 10 workstations and one cutting edge high performance dual processor LINUX Workstations. All the operating system of Linux stations were kept maintained to the latest RedHat Linux with PVM package. All LINUX and Sun stations were equipped with FORTRAN and C compilers. In the past six years, legacy high performance computing codes, such as GENIE++, FDNS, WIND, RPLUS, and Burnett -3D (developed by current authors to compute transitional and micro-channel flow) were installed. Benchmark testing of these codes was completed. Figure 1 shows the setup of the HPC lab.

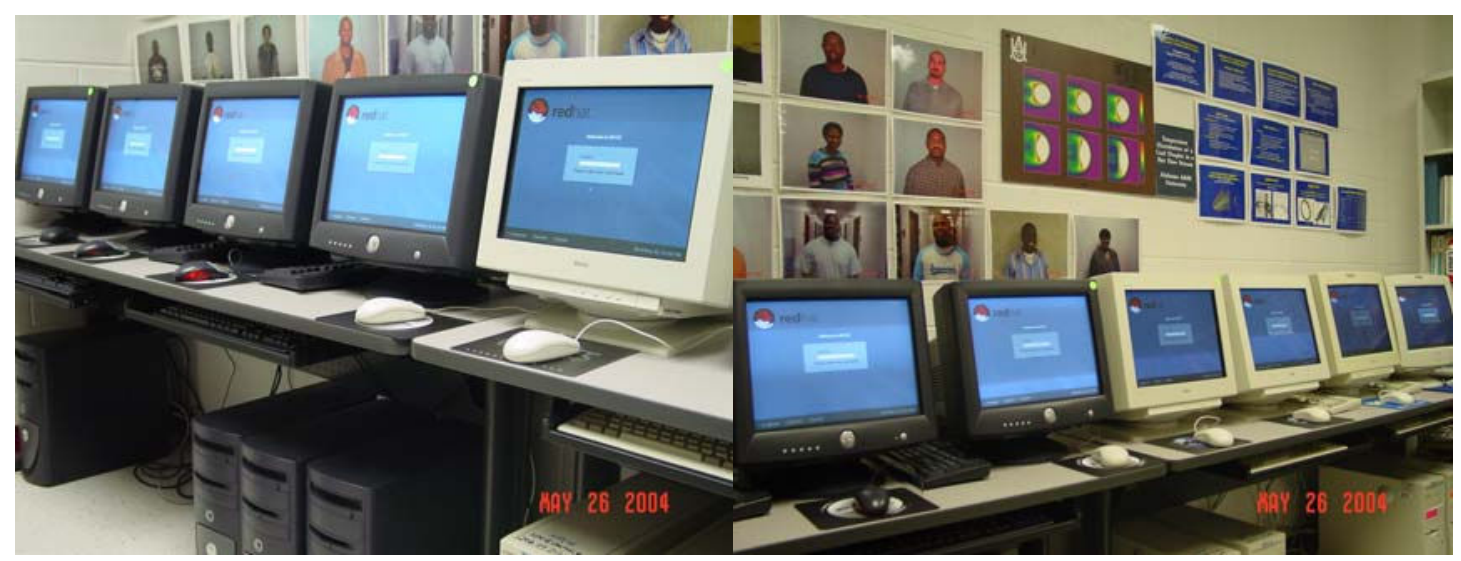

Figure 1. The High Performance Computing Laboratory at AAMU.

Research on plume signature, micro-scale transitional flow and plasma dynamics were conducted. Scientific data visualization software was also installed. These workstations were networked on a 10/100 Base-T Ethernet network. High Performance Computing concept was implemented in Mathematical Methods in Mechanical Engineering, and heat transfer classes. For example, in heat transfer class, students were required to develop a computer code to model two-dimensional heat conduction. Parallel computing concepts were introduced. As a result of this teaching effort, the summer interns of 2002 and 2003 were able to extend the heat transfer computing project to conduct parallel computation for three-dimensional heat conduction.

The HPC Laboratory is available for use by project participants and by researchers, faculty and students at Alabama A\&M University. Students from Mechanical Engineering, Electrical 
Engineering, Civil Engineering, Chemistry, and the Computer Science Departments, were encouraged to use the cluster for parallel computing. The enhanced high performance computing lab has been a showcase of the university for government and industry visitors and researchers. Many presentations have been given to visitors and potential collaborators in the area of high performance parallel computing in combustion, transitional fluid dynamics and plasma propulsion.

\section{Research and Training in Computational Science and Engineering}

In the past six years, three graduate research assistants and five undergraduate research assistants were trained in parallel computing, computational science and engineering. Figure 2 shows the comparison between experimental and computational results in plume signature. The simulation was performed using WIND code in the HPC lab.

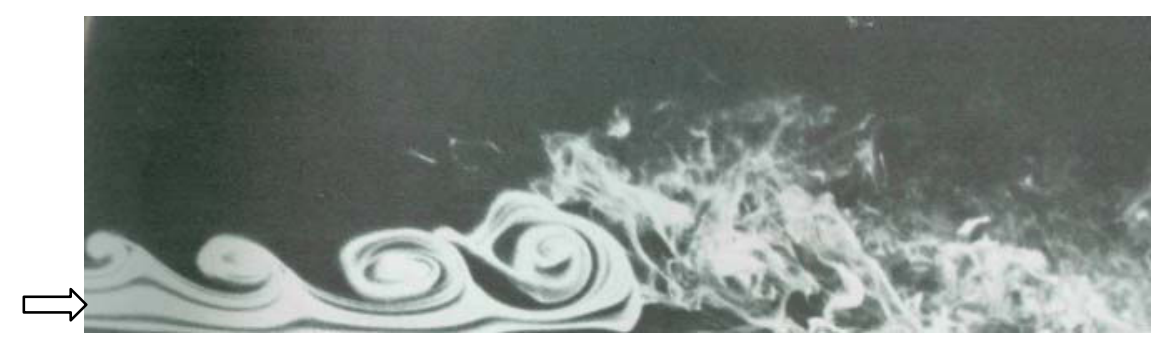

Cold Jet / Cold Air - Flow Image

Experiment (Robert Drubka and Hassan Nagib [4], Stanford University)

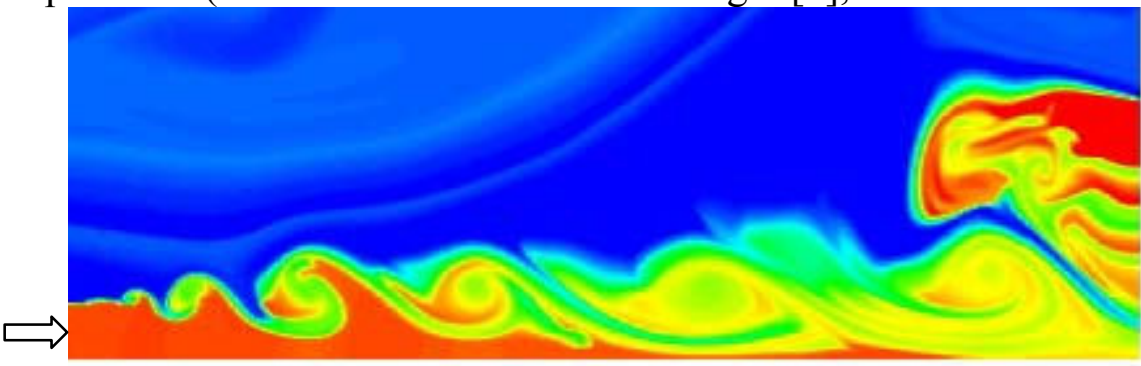

Simulation Results -Temperature Contours

Figure 2. Comparison of axisymmetric jet plume signature between experimental data and simulation using WIND.

In the past six years, three Assistant Professors in school of engineering and technology at AAMU were supported to attend workshops in parallel computing and leadership computing at University of Tennessee, University of Kentucky and ORNL. During these workshops, research capabilities were exchanged, and potential collaboration between AAMU and ORNL Computational Science division was made.

Faculty and student research assistants at AAMU were also supported to participate in several NASA's conferences, ORNL annual high performance computing workshop, and AAMU business and industry cluster conferences. As a by-product of this DOE sponsored project, a joint research proposal with University of Alabama at Birmingham was submitted to National Science Foundation in June, 2003. A collaboration research proposal with NASA 
and Industry was submitted to US Army Missile Command in April 2005 and was successfully funded.

\section{DOE Computational Science Scholarship}

In the academic year of 1999, AAMU created a DOE Computational Science Scholarship program through the DOE project. This program was continued through 2005. Over 60 students have benefited from this program. Among our past students is a USA Today 1999 Academic Second Team member. Only 20 students nationwide are selected for each team. One scholarship recipient was a member of the first graduating class (May 1999) to obtain B.S. degrees in ME at AAMU.

The scholarship application announcement and application form were posted on the HPC web-site, university admission office and departments of Mathematics, Physics, Chemistry, Biology, Computer Science, Mechanical Engineering, Electrical Engineering and Civil Engineering on the campus. A scholarship award selection criterion was developed. During the annual high-school senior day at AAMU, the scholarship announcement was handed out to high-school graduating seniors. Many students inquired about the scholarship program and have shown great interest. To apply for the scholarship, students need to fill out the application form, write an essay about their goal towards high performance computing, along with a faculty recommendation letter. Upon receipt of the application package, careful evaluation was conducted based on the scholarship criteria. Students agree to maintain a GPA of 3.0, successfully complete a minimum of 12 credit hours per semester, and maintain a major in science, mathematics and engineering. Student will have to pay for any course that they fail and/or receive an incomplete grade, and they are responsible for any fees in the excess of the minimum amounts provided by DOE. Students are also required to accept employment with the Department of Energy each year if offered. After careful evaluation by the scholarship committee, scholarship awards were announced. Candidates will need to sign acceptance form in order to receive the scholarships. This form re-iterates the requirements and obligation as a scholarship recipient. In the past six years, 60 undergraduate scholarships were awarded to science and engineering students. Each award is $\$ 1500$. Tables 1 listed the scholarship recipient information in academic year of 2003-2005. Figure 3 shows the GPA distribution of scholarship recipients in 2003-2005. It is indicated that the majority of the scholarship recipients had GPA better than 3.8. This posted a challenge to us: how to attract "average" African American students to the field of computational science? What is the necessary modification we have to make to achieve this? Further studies are needed to answer these challenges. Table 2 shows some tracking record of scholarship recipients in 2004.

Table 1. Scholarship Recipient Information for 2003-2005 at AAMU

Total Number of Awards: 30

\begin{tabular}{|c|l|c|}
\hline \multirow{3}{*}{ Gender } & Male & $73 \%$ \\
\cline { 2 - 3 } Race & Female & $27 \%$ \\
\hline \multirow{3}{*}{} & African American & $90 \%$ \\
\cline { 2 - 3 } & American Indian & $10 \%$ \\
\hline & Engineering and Technology & $73 \%$ \\
\hline
\end{tabular}




\begin{tabular}{|c|l|c|}
\hline Major & Math and Science & $27 \%$ \\
\hline
\end{tabular}

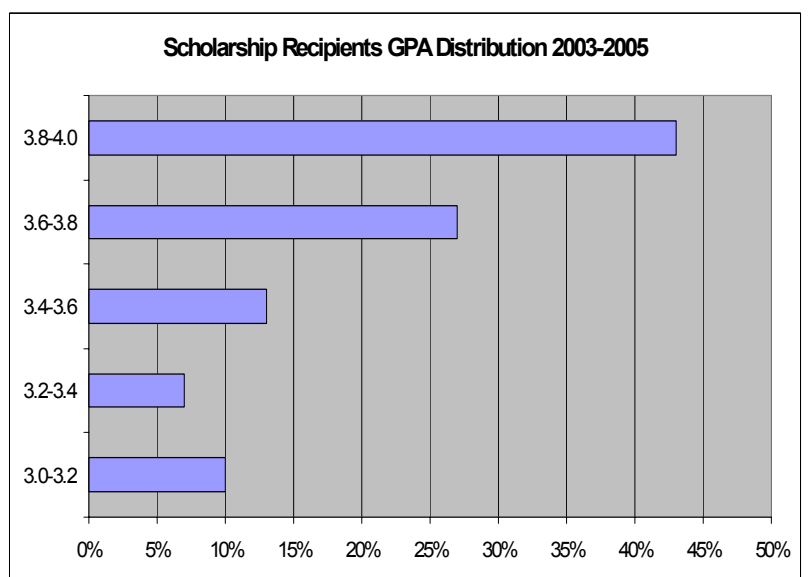

Figure 3. Computational Science Scholarship Recipients GPA Distribution in 2003-2005.

Table 2. Special Characteristics Scholarship Recipients in 2004 at AAMU

\begin{tabular}{|l|l|l|}
\hline $\begin{array}{l}\text { Scholarship } \\
\text { Recipient }\end{array}$ & Special Interests & Current Status \\
\hline $\begin{array}{l}\text { Female } \\
\text { African American }\end{array}$ & $\begin{array}{l}\text { Strong interest in mathematics, } \\
\text { physics and engineering. }\end{array}$ & $\begin{array}{l}\text { NASA Dryden Flight Center 2004 Summer } \\
\text { Interns, Conducting Propulsion Simulation } \\
\text { Graduated in 2005. Currently working at Rolls- } \\
\text { Royce Corp. Attending Purdue University } \\
\text { Graduate School, major in Mechanical } \\
\text { Engineering. }\end{array}$ \\
\hline $\begin{array}{l}\text { Male } \\
\text { African American }\end{array}$ & $\begin{array}{l}\text { Strong desire to obtain } \\
\text { graduate degree in science and } \\
\text { engineering. }\end{array}$ & $\begin{array}{l}\text { Summer Interns at Heat Exchanger Design } \\
\text { company in Birmingham, Alabama. Graduated in } \\
\text { 2005. Currently attending Graduate School of } \\
\text { University in Alabama, Mechanical Engineering. }\end{array}$ \\
\hline $\begin{array}{l}\text { Male } \\
\text { African American }\end{array}$ & $\begin{array}{l}\text { Analytical, computational and } \\
\text { intuitive skills. Desire in } \\
\text { Simulation of laser ignition of } \\
\text { energy conversion. }\end{array}$ & $\begin{array}{l}\text { NASA Marshall Space Flight Center summer } \\
\text { interns doing material processing research. } \\
\text { Graduated in 2005. Currently attending Graduate } \\
\text { School of University of Alabama in Huntsville. }\end{array}$ \\
\hline $\begin{array}{l}\text { Male } \\
\text { African American }\end{array}$ & $\begin{array}{l}\text { Computational simulation of } \\
\text { propulsion system. }\end{array}$ & $\begin{array}{l}\text { NASA Marshall Space Flight Center summer } \\
\text { interns doing computational heat transfer for } \\
\text { propulsion system. Graduated in 2005. Currently } \\
\text { attending Graduate School of Georgia Tech. }\end{array}$ \\
\hline $\begin{array}{l}\text { Male } \\
\text { African American }\end{array}$ & $\begin{array}{l}\text { Strong desire to work for DOE } \\
\text { on computational science. } \\
\text { Analytical and programming } \\
\text { skill. }\end{array}$ & $\begin{array}{l}\text { Oak Ridge National Lab RAM summer intern } \\
\text { working on a new local minimization algorithm } \\
\text { for TRUST global optimization code. Requires to } \\
\text { learn quantum computing. Employed by NASA } \\
\text { MSFC in January 2007. }\end{array}$ \\
\hline $\begin{array}{l}\text { Female } \\
\text { African American }\end{array}$ & $\begin{array}{l}\text { Mathematical and } \\
\text { programming skill. Strong } \\
\text { desire in working towards high } \\
\text { performance computing. } \\
\text { Determined to obtain Master } \\
\text { of Science Degree in } \\
\text { Engineering }\end{array}$ & $\begin{array}{l}\text { Graduated in 2006. Working for US AMCOM. } \\
\text { Attending Graduate School. }\end{array}$ \\
\hline $\begin{array}{l}\text { Boeing Scholar, Graduated in 2006. Working for } \\
\text { Boeing Company. Attending Graduate School. }\end{array}$ \\
\hline
\end{tabular}


The DOE Scholarship program increased the minority student's interests in pursuing a career toward computational science fields. We have found that the scholarship program provided an excellent way to attract sophomore and junior students at Alabama A\&M University. We have been able to recruit the best science and engineering students to apply for the DOE Computational Science scholarship so far. With the scholarship obligation, students are willing to maintain their high academic standards and stay in the field of engineering or science. Out of the sixty scholarship recipients three are currently working for the Department of Energy in the area of computational science and attending graduate school supported by DOE.

\section{Student Summer Internship at ORNL}

ORNL Computational Science summer internship program (RAMS) announcement was posted around the AAMU campus in early February of each year in the Department of physics, mathematics, chemistry, biology, mechanical engineering, electrical engineering, civil engineering and computer science. Through the DOE project, AAMU was able to identify and support ten students to participate the summer research at ORNL. In the last six years, with the assistance of ORNL, six more undergraduate students were supported for ten week study at ORNL in the summer. In summer 2005, one student published a research paper with ORNL scientists entitled, "Discovery of New Global Minima for Lennard - Jones Atomic Clusters Using TRUST Simulations". Student performance was closely monitored by joint effort of AAMU faculty mentor and ORNL project director and scientist mentor. At the end of their summer interns, outcome of the research was evaluated by written report and oral presentation, which was judged by ORNL scientists and faculty mentors from HBCUs in Tennessee, Alabama, North Carolina and Georgia. Summer interns from AAMU were also required to present their research results at the workshop on campus.

\section{Assessment}

The high-performance computing research and education activities were externally evaluated annually by a panel formed by U.S. Department of Energy Computational Science Division. The project outcome was evaluated by DOE, and funding was renewed by DOE based on program merit. The key factors determining success of the program is to attract and educate top minority graduate and undergraduate students in the field related to computational science. Each scholarship recipient's academic performance is evaluated annually by faculty members. Graduate and undergraduate research assistant's performance was evaluated based primarily on required research tasks. Summer internship performance was assessed by DOE Scientist and HBCU faculty mentor.

\section{Conclusion}

Thanks to the support of DOE in the past six years, AAMU was able to award over 60 DOE computational science scholarships to top minority engineering students. Ten engineering undergraduate summer research interns were supported to work with scientists at DOE Oak Ridge National Laboratory. Four graduate students were supported through research assistantships. Five undergraduate research assistants were trained in computational science. 
In 2005, of the 60 minority scholarship recipients, 12 were actively attending graduate schools in science and engineering field. Three DOE Scholarship recipients are currently working for DOE. It was proved that this project created a huge attraction to top minority engineering students and greatly enhanced engineering education to minority students.

\section{Bibliography}

[1]. DOE Alliance for Computational Science Collaboration (ACSC) FY00 STRATEGIC PLAN.

[2]. Z.T. Deng, Cathy Qian and Scott von Laven, "Alliance for Computational Science Collaboration: HBCU Partnership at Alabama A\&M University”, Final Report, (DE-FG02-98ER25366), November 2001.

[3]. Z.T. Deng and Cathy Qian, "Enhancing High Performance Computing Research and Education at AAMU, DOE Final Report, (DE-FG02-02ER25545), December 2005.

[4]. Milton Van Dyke, An Album of Fluid Motion, The Parabolic Press, 1997. 